\title{
A novel Respiratory Health Score (RHS) supports a role of acute lung damage and pig breed in the course of an Actinobacillus pleuropneumoniae infection
}

\author{
Doris Hoeltig1, Isabel Hennig-Pauka1, Kerstin Thies ${ }^{1}$, Thomas Rehm², \\ Martin Beyerbach ${ }^{3}$, Katrin Strutzberg-Minder ${ }^{4}$, Gerald F Gerlach*+2, Karl- \\ Heinz Waldmann ${ }^{\dagger 1}$ and FUGATO-consortium IRAS
}

\begin{abstract}
Address: ${ }^{1}$ Clinic of Swine and Small Ruminants, Forensic Medicine and Ambulatory Service, University of Veterinary Medicine Hannover, Bischofsholer Damm 15, 30173 Hannover, Germany, ${ }^{2}$ Institute for Microbiology, Department of Infectious Diseases, University of Veterinary Medicine Hannover, Bischofsholer Damm 15, 30173 Hannover, Germany, ${ }^{3}$ Department of Biometry, Epidemiology and Information Processing, University of Veterinary Medicine Hannover, Bünteweg 2, 30559 Hannover, Germany and 4IVD GmbH, Heisterbergallee 12, 30435 Hannover, Germany

Email: Doris Hoeltig - doris.hoeltig@tiho-hannover.de; Isabel Hennig-Pauka - isabel.hennig@tiho-hannover.de;

Kerstin Thies - kerstin.thies@tiho-hannover.de; Thomas Rehm - threhm@t-online.de; Martin Beyerbach - martin.beyerbach@tiho-hannover.de; Katrin Strutzberg-Minder - strutzberg@ivd-gmbh.de; Gerald F Gerlach* - gfgerlach@gmx.de; Karl-Heinz Waldmann - karlheinz.waldmann@tiho-hannover.de; FUGATO-consortium IRAS - gfgerlach@gmx.de

* Corresponding author †Equal contributors
\end{abstract}

Published: 21 April 2009

BMC Veterinary Research 2009, 5:14 doi:10.1 186/1746-6/48-5-14
Received: 23 October 2008

Accepted: 21 April 2009

This article is available from: http://www.biomedcentral.com/I746-6/48/5/14

(C) 2009 Hoeltig et al; licensee BioMed Central Ltd.

This is an Open Access article distributed under the terms of the Creative Commons Attribution License (http://creativecommons.org/licenses/by/2.0), which permits unrestricted use, distribution, and reproduction in any medium, provided the original work is properly cited.

\begin{abstract}
Background: Bacterial lung infections are a major cause of economic losses in the pig industry; they are responsible for approximately $50 \%$ of the antibiotics used in pigs and, therefore, also present an increasing concern to consumer protection agencies. In response to this changing market we investigated the feasibility of an old approach aimed at the breeding selection of more resistant pigs. As a first step in this direction we applied a new respiratory health score system to study the susceptibility of four different pig breeding lines (German Landrace, Piétrain, Hampshire, Large White) towards the respiratory tract pathogen Actinobacillus (A.) pleuropneumoniae.

Results: A controlled experimental aerosol infection with an A. pleuropneumoniae serotype 7 isolate was performed using 106 weaning pigs of defined breeding lines from the breeds German Landrace, Piétrain, Hamphire, and Large White. Pigs were clinically assessed on days 4 and 20 post infection following a novel scoring system, the Respiratory Health Score (RHS), which combines clinical, sonographic and radiographic examination results. The ranking on day 4 was significantly correlated with the ranking based on the pathomorphological Lung Lesion Score (LLS; Spearman Rank Correlation Coefficient of 0.86 [p $<0.000$ I]). Based on their RHS pigs were assigned to the different quartiles independent of the breeding line. The RHS-based rankings of pigs on day 4 and on day 20 were highly correlated (Spearman Rank Correlation Coefficient of $0.82[\mathrm{p}<0.000 \mathrm{I}]$ ) independent of the breeding line. Pigs of the Hampshire line were predominantly found in the lowest scoring quartile (47.6\%) and absent in the highest scoring quartile. In contrast, pigs of the German Landrace and Piétrain breeding lines were predominantly found in the highest scoring quartile ( $32.3 \%$ and $35.7 \%$, respectively).

Conclusion: These results demonstrate that the RHS obtained from live pigs shows a highly significant correlation to the lung lesion score considered as a "gold standard". The correlation of the ranking at days 4 and 20 post infection implies that the course of disease is highly dependent on the acute lung damage. The different severity of signs among the tested pig breeding lines clearly suggests a genetic difference in the susceptibility of pigs to A. pleuropneumoniae infection.
\end{abstract}




\section{Background}

Bacterial respiratory diseases caused by Mycoplasma hyopneumoniae, Actinobacillus pleuropneumoniae, and Haemophilus parasuis are of major importance in the pig industry [1-3]. They cause severe economic losses due to premature deaths and reduced daily weight gains [4]. Currently, productivity in infected herds is improved by antibiotic treatment and by vaccination regiments. However, vaccination efficacy is hampered by limited cross-serovar protection $[5,6]$, and treatment is impeded by the increasing occurrence of resistant strains [7]. In addition, in recent years the interest of consumers in quality assurance along the pork production chain has greatly heightened. Thus, today there is a strongly increasing demand for pork obtained from healthy animals not subjected to treatment during the fattening period $[8,9]$.

In response to this changing market an old approach aimed at the breeding selection of more resistant pigs has gained renewed attention. In the past it could be shown that breed is an important factor influencing the baseline immune traits and, therefore, the response to various stressors or infectious challenges [10]. For example, the susceptibility of pigs towards E. coli K88 which was identified to be of monogenic origin has been successfully suppressed by a targeted breeding approach [11,12]. More recently, Reiner et al. showed that different breeds have distinct susceptibilities towards Pseudorabies virus [13] and Sarcocystis miescheriana [14]; QTL-mapping revealed that increased resistance to these pathogens is a complex trait. Also in the field of avian [15], ovine [16] and bovine diseases [17] natural resistance to different pathogens could be ascertained and used for the selection of a breeding population with increased resistance.

Concerning respiratory diseases of pigs a number of studies dealing with breed-dependent susceptibility towards viral infection (PCV-2, PRRSV) have been performed [1822]. All of these studies provide strong evidence for genetic factors accountable for differences in susceptibility towards viral lung infections. In addition, a number of studies implied that there also is an influence of breed on the mortality of pigs suffering from bacterial lung infection [23-26].

The availability of increasing molecular information and new technologies such as i) a draft sequence of the porcine genome, ii) whole genome expression arrays, and iii) a porcine single nucleotide polymorphism (SNP) chip with 50.000 SNP now potentially facilitate the investigation of complex traits. As a first step in this direction we investigated the susceptibility of four different pig breeding lines (German Landrace, Piétrain, Hampshire, Large White) to infection with A. pleuropneumoniae. In order to minimize environmentally-induced variability, all pigs originated from the same herd and were subjected to experimental aerosol infection in a well-established $A$. pleuropneumoniae model [27-30]. All animals were phenotyped using an elaborate clinical investigation scheme including sonography and radiography before infection as well as on days 4 and 20 post infection [31], and a clinical assessment system, the Respiratory Health Score (RHS) was developed. Including all clinical investigation results this RHS facilitates an exact determination of the lung status in the living pig. Therefore, unlike the Lung Lesion Score (LLS), which is used as gold-standard for lung investigations until now [32], the RHS allows the comparison of the lung status at different time points after infection. The animals were consecutively ranked according to disease severity in acute (day 4) and chronic infection (day 20). Subsequently, the ranking of animals on both days and the number of animals from different breeding lines in the ranking quartiles were compared.

\section{Results \\ Development and validation of the Respiratory Health Score (RHS)}

Upon infection the severity of clinical symptoms ranged from no symptoms to death. Clinical symptoms were typical for A. pleuropneumoniae infection with body temperatures up to $41.9^{\circ} \mathrm{C}$, dyspnoea, coughing and apathy; likewise, ultrasonographic and radiographic results with comet tail artefacts, interruption of the pleural line, liverlike parenchyma texture, abscesses, bronchography, and increasing lung opacity were typical for porcine pleuropneumonia.

Of the 106 pigs challenged 103 pigs entered the study; all these pigs had a RHS of zero at day 7 pre-infection and tested negative for A. pleuropneumoniae, Mycoplasma hyopneumoniae, Influenca-A-Virus and PRRSV by antibody ELISA. Due to severe clinical symptoms 11 pigs died or were euthanized outside of days 4 and 20 and, therefore, could not be included in the subsequent ranking. Of the remaining 92 pigs 47 were sacrificed on day 4 and 45 on day 20 post infection, respectively. For each of these pigs a daily clinical score was determined and, together with the results of the ultrasonographic and radiographic lung examination, was used to calculate the RHS (Fig. 1). In addition, at necropsy the LLS was determined for each of these pigs. Pigs were then ranked based on RHS and LLS; the Spearman Rank Correlation Coefficient comparing both ranking scores was determined to be 0.86 and 0.81 ( $\mathrm{p}<0.0001$ ) on day 4 (Fig. 2a) and on day 20 (Fig. 2b), respectively.

\section{Comparative ranking of pigs on days 4 and 20 post infection}

The RHS facilitated a comparative ranking of pigs on days 4 and 20 post infection, and this was performed for 45 


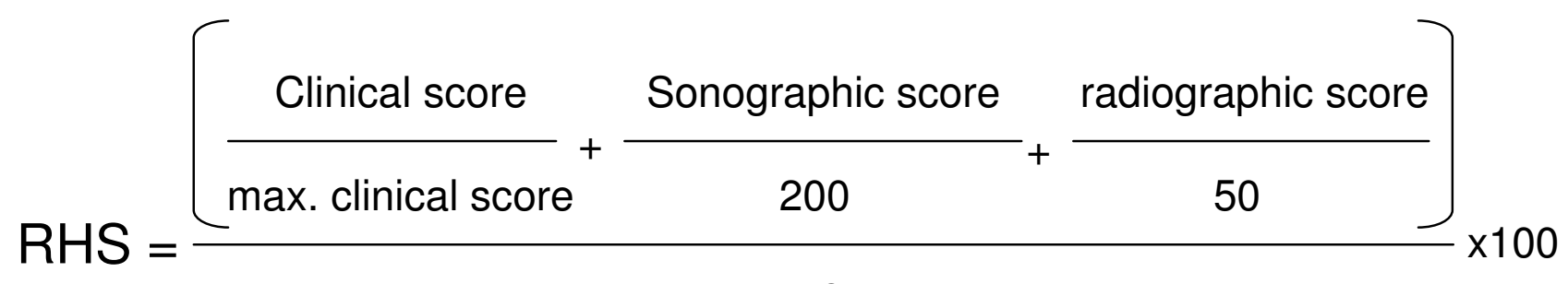

3

\section{Figure I}

Algorithm for calculating the Respiratory Health Score (RHS). Clinical, sonographic and radiographic scores were normalized by division with the score causing death in an animal, added, divided by three and multiplied by 100 in order to get a value in percent. The RHS has a possible range from 0 to $100 \%$. The maximum clinical score on days 4 and 20 is 20 and 100 , respectively.

pigs sacrificed on day 20 post infection (Fig. 3). A close correlation (Spearman rank correlation coefficient of 0.82 ) was observed and was found to be highly significant ( $\mathrm{p}<0.0001$; Fig. 3).

\section{Susceptibility of different breeding lines upon infection with A. pleuropneumoniae}

Eleven of 38 German Landrace pigs died or were euthanized due to severe clinical symptoms before day 4 or between day 4 and day 20. All pigs of the other breeding lines survived. The RHS-based ranking of all surviving pigs was performed on day 4 and 20 post infection. In order to assess the relative disease severity within the different breeding lines ranking quartiles were formed (Table 1), and the distribution of the different breeding lines within these quartiles was ascertained (Tables 2,3 ). It was apparent that pigs of the Hampshire breeding line were clearly less susceptible to an A. pleuropneumoniae infection showing no mortality and no animals in the $4^{\text {th }}$ ranking quartile at both day 4 and day 20 post infection. The other three breeding lines showed no clear differences with respect to the RHS; thus in all lines at least $50 \%$ of the pigs were ranked in the $3^{\text {rd }}$ or $4^{\text {th }}$ quartile. When considering mortality in addition to the RHS, pigs of the German Landrace breeding line appeared to be most susceptible to $A$. pleuropneumoniae infection.

\section{Discussion}

The intention of this study was to establish a combined quantitative scoring system to determine the lung status of diseased pigs avoiding the necessity of necropsy. All individual examination methods had been established previously, and the resulting individual scores (clinical, ultrasonographic and radiographic score) had been evaluated [31,33-36]. However, none of these scores resulted in a ranking of pigs that correlated with the LLS considered as "gold standard". In the current work we examined the suitability of a combined score designated as Respiratory
Health Score (RHS) including the clinical score and both ultrasonographic and radiographic examination of the lungs, as lung tissue alterations do not inevitably lead to clinical symptoms. These lung tissue alterations, however, can be visualized using imaging techniques with both radiographic and ultrasonographic examination methods having different limitations [37-42]. Also, neither ultrasonography nor radiography alone accurately depict the severity of lung tissue alterations. While affections of the pleura as well as sequestration of lung tissue at the lung surface could be clearly identified during the ultrasonographic examination, deep tissue alterations with no contact to the lung surface could only be detected radiographically. Using both methods, however, allows a comprehensive evaluation of the lung condition [31]. For this reason the results of both methods are combined with the clinical score to result in a single value, the RHS. The RHS and the LLS are significantly correlated and, therefore, the RHS was considered appropriate as an alternative to the LLS. Since both imaging techniques can only be performed under anaesthesia the frequency of investigations is limited as immunosuppressive effects from anaesthesia cannot be excluded. In our experimental design we kept at least 14 days between two subsequent anaesthesias thereby minimizing possible detrimental effects. Despite these limitations the RHS, in our hands, is an excellent tool for all scientific investigations, where consecutive quantifications of the lung status during the course of disease in individual pigs are required.

The RHS system was applied to investigate the ranking of pigs in acute (day 4) and chronic infection (day 20 post infection). This comparison of RHS in the acute and chronic stages of disease was done to investigate the impact of the acute lung damage on the course of disease upon A. pleuropneumoniae infection. In the past, pigs with a low adaptive immune response have been compared to those with a high adaptive immune response [43]; the lat- 

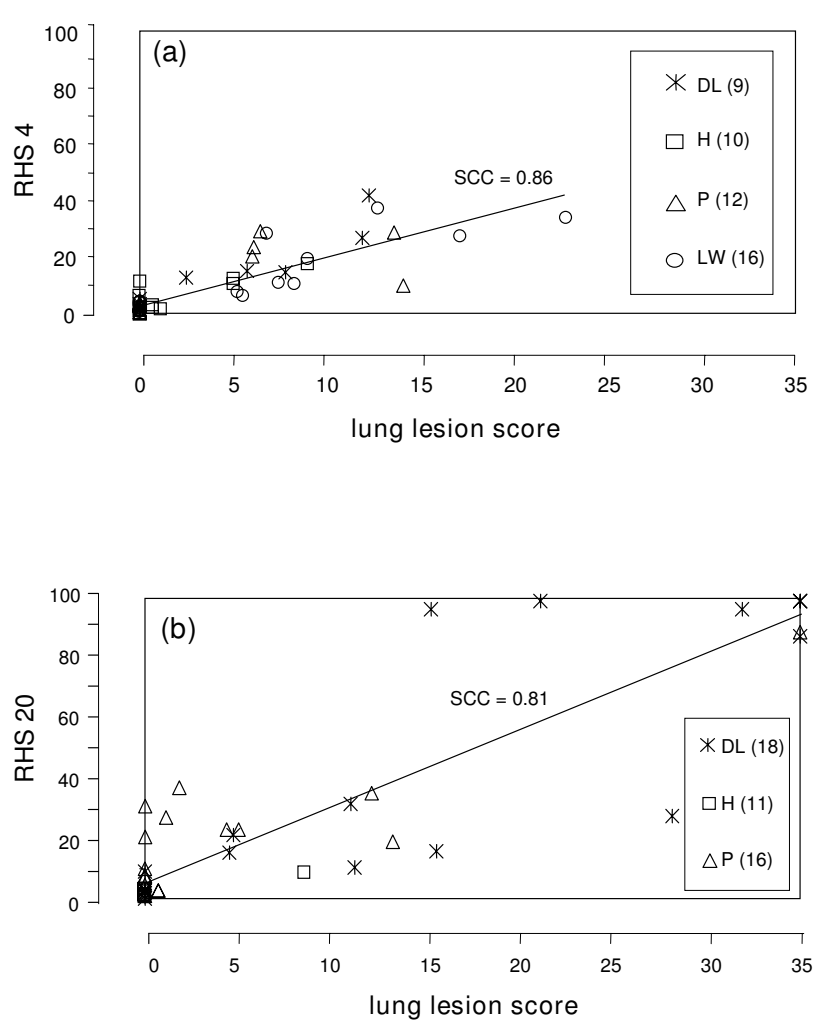

Figure 2

Correlation of RHS and lung lesion score on day 4 (a), and on day 20 post infection (b). The Spearman Rank Correlation coefficient (SCC) was calculated using 47 (a) and 45 pigs (b), respectively, and was highly significant ( $P$ $<0.000$ I) for both time points. The number of pigs with a LLS of 0 was $2 \mathrm{I}$ (a) and 23 (b), respectively. DL = German Landrace, $\mathrm{H}=$ Hampshire, $\mathrm{P}=$ Piétrain, $\mathrm{LW}=$ Large White; the number in parenthesis indicate the number of pigs of each breeding line.

ter were then selected for breeding [44] hypothesising that these pigs might show an increase in general resistance to infectious diseases. However, since the degree of acute lung damage which is modulated by the innate immune system appears to have a strong impact on the course of disease the innate immune system might also play an important role in disease development.

Investigating possible differences among the breeding lines used in the study, various environmental factors with a potential influence on susceptibility such as origin of the pigs, age, and infectious dose were all standardized. Sex as another potential factor had been shown previously to not influence the course of disease [24]. Other factors such as the social hierarchy within groups, differences in physical development between breeds [24], and the ability to adapt to new environments (e.g. unfamiliar management procedures or facilities, climate, herd size, or the contact to ubiquitous and contaminating microorganisms) were minimized by the experimental set-up in this study $[45,24,46]$. Thus, environmental and management conditions were highly standardized, and experiments were performed in groups containing a single breed as well as in groups containing different breeds.

The result of this study confirmed the low susceptibility of Hampshire pigs that had been described previously [24]. Likewise, the previously described susceptibility within the breeds of Large White and German Landrace [23] was confirmed, and pigs of the Piétrain breeding line were found to be equally susceptible based on the RHS. The greater susceptibility of Large White pigs compared to the German Landrace pigs that was described after bacterial lung infections as well as after PCV-2 infections by other workers $[23,18]$ could not be observed. In contrast, the German Landrace pigs have to be considered as most susceptible as only pigs of this breeding line died or had to be euthanized due to severe clinical symptoms. This difference may be due to differences between local breeding lines or simply caused by the small number of Large White pigs in this study.

The genetic mechanisms responsible for the differences observed in susceptibility to A. pleuropneumoniae serotype 7 infection are still unknown; since the general mechanisms of pathogenicity are species-specific we expect similar results upon infection with other A. pleuropneumoniae serotypes. Future studies on this subject will be greatly facilitated by the finding that the acute lung damage appears to be decisive for the course of disease which allows termination of infection experiments on day 4 post infection without loss of information. Therefore, this work is considered to be an essential first step in the development of genetic markers that could be used for a breeding selection aimed at the increase of resistance to $A$. pleuropneumoniae infection. In addition, it might facilitate studies investigating genetic resistance of pigs to other bacterial respiratory tract pathogens.

\section{Conclusion}

In the course of these studies we demonstrated that the Respiratory Health Score (RHS) developed shows a highly significant correlation to the Lung Lesion Score (LLS) considered as a "gold standard". Therefore, the RHS allows the comparison of the lung status at different time points during infection in the same pig. The results of the lung status comparison between acute and chronic stage of pleuropneumonia strongly suggests that the acute lung damage is decisive for the course of disease. Furthermore, the different severity of symptoms among the tested breeding lines clearly implies that they have a highly distinct genetic susceptibility to A. pleuropneumoniae infection. 


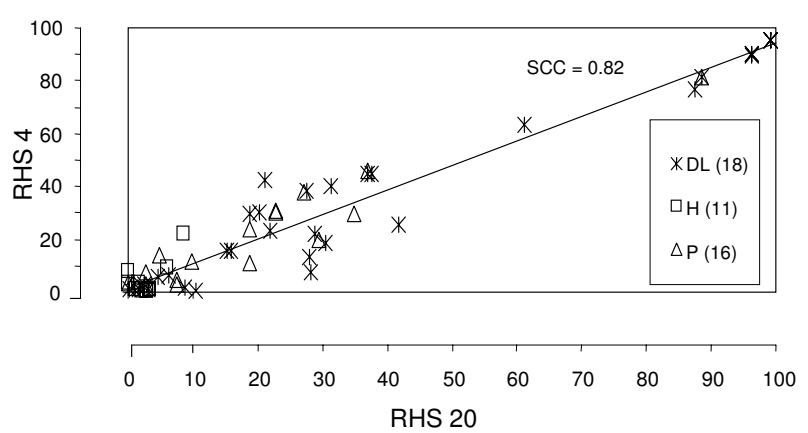

Figure 3

Correlation of RHS on days 4 and 20 post infection. The Spearman Rank Correlation coefficient (SCC) was calculated to using 45 pigs and was highly significant $(p<0.000 \mathrm{I})$. $\mathrm{DL}=$ German Landrace, $\mathrm{H}=$ Hampshire, $\mathrm{P}=$ Piétrain, $\mathrm{LW}=$ Large White; the number in parenthesis indicate the number of pigs of each breeding line.

\section{Methods}

\section{Animals, animal housing, and time course}

A total of 106 pigs (40 German Landrace, 28 Pietrain, 22 Hampshire, 16 Large White) were infected. Three pigs (two German Landrace, one Hampshire) were not included into the study since the had contracted Oedema Disease. Due to severe clinical symptoms seven animals died or were sacrificed before day 4, and four animals were sacrificed after day 4 and before day 20 (all German Landrace). Thus, for 92 pigs (27 German Landrace, 28 Piétrain, 21 Hampshire, 16 Large White) both, a RHS and a LLS could be obtained. Of these, 47 pigs ( 9 German Landrace, 12 Piétrain, 10 Hampshire, 16 Large White) were randomly selected and sacrificed on day 4 ; the remaining 45 pigs (18 German Landrace, 16 Piétrain, 11 Hampshire) were sacrificed on day 20 post infection. Material from the same pigs was simultaneously used in a parallel study investigating expression levels of immune markers in relation to breeding line and the disease severity [47].

Table I: Range of RHS-points within the ranking quartiles at 4 and 20 days post infection

\begin{tabular}{|c|c|c|}
\hline & $\begin{array}{l}\text { day } 4 p . \inf \\
(n=96)\end{array}$ & $\begin{array}{l}\text { day } 20 \mathrm{p} \text {. inf. } \\
\quad(\mathrm{n}=45)\end{array}$ \\
\hline $\begin{array}{c}\text { Ist quartile } \\
\text { (no symptoms) }\end{array}$ & $0-2.1$ & $0.21-3.33$ \\
\hline $\begin{array}{c}2^{\text {nd }} \text { quartile } \\
\text { (mild symptoms) }\end{array}$ & $2.11-10.7$ & $3.34-18.8$ \\
\hline $\begin{array}{c}3^{\text {rd }} \text { quartile } \\
\text { (moderate symptoms) }\end{array}$ & $10.7 \mid-27.5$ & $|8.8|-34.9 \mid$ \\
\hline $\begin{array}{c}4^{\text {th }} \text { quartile } \\
\text { (severe symptoms) }\end{array}$ & $27.5 I-95.6 I$ & $34.92-99.12$ \\
\hline
\end{tabular}

At the time of infection pigs were 6 to 7 weeks old and were tested negative for A. pleuropneumoniae using an ApxIIA [48] and an ApxIVA ELISA [49]. In addition, all pigs tested negative for Mycoplasma hyopneumoniae and PRRS by antibody ELISA (HerdChek*, IDEXX Laboratories, Westbrook, Maine, USA), and Influenca-A-Virus by hemagglutination inhibition test using porcine H1N1, H1N2 and H3N2 strains. During the entire time (before and after infection) pigs were kept under standardized containment level 2 conditions with $8 \mathrm{~m}^{2}$ floor space per 10 pigs, with standardized climate and diet, and cared for in accordance with the principles outlined by the European Convention for the Protection of Vertebrate Animals used for Experimental and Other Scientific Purposes (European Treaty Series, nos. $123 \mathrm{http}: / /$ conventions.coe.int/treaty/ EN/treaties/html/123.htm and 170 http://conven tions.coe.int/treaty/EN/treaties/html/170.htm; approval number: 33-42502-05/941). In order to reduce the impact of stress on the examination results pigs were randomised into different groups at the age of four weeks and accustomed to handling over a one- to two-week period prior to aerosol infection. The examination period lasted four weeks, from seven days before until 20 days after infection. Radiography and sonography were done three times, namely on day 7 before and on days 4 and 20 after infection.

At the end of the experiment pigs were necropsised; the lung damage was quantified using the Lung Lesion Score (LLS) proposed by Hannan et al. [32] and specified in the European Pharmacopoeia for the testing of A. pleuropneumoniae vaccines (3 rd edn., EDQM, Council of Europe, Strassbourg, France). The LLS is determined after the removal of the lungs from the thorax in the course of necropsy. The lungs are palpated and areas of non-physiological consistence are recorded in a schematic map of the porcine lung. In this map the pulmonary lobes are subdivided into triangles ( 7 triangles for each, cranial and middle lobes, 19 triangles for caudal lobes, and 8 triangles for the Lobus accessories). In the LLS (maximum value of 35 ) each lobe contributes a maximum score of 5 (tissue damage in the entire lobe). To determine the LLS the damaged area is determined by counting the number of triangles indicating tissue damage and expressing it as a fraction of five for each lobe. The values for each of the seven lobes are added to result in the LLS.

\section{Experimental infection and clinical investigation}

Aerosol infection was performed using A. pleuropneumoniae serotype 7 strain AP76 as previously described $[50,51]$; during infection approximately $1 \times 10^{5}$ bacteria were nebulised for five pigs resulting in an aerosol with 1 $\times 10^{2}$ colony forming units (cfu) of A. pleuropneumoniae per litre aerosol. 
Table 2: RHS-based distribution of pigs from different breeding lines into ranking quartiles on day 4 post infection

\begin{tabular}{|c|c|c|c|c|}
\hline & |st quartilel) & $2^{\text {nd }}$ quartile 2 ) & $3^{\text {rd }}$ quartile $)^{3)}$ & $4^{\text {th }}$ quartile ${ }^{4)}$ \\
\hline German Landrace $^{5)} n=27$ & $16.1 \%$ & $29.0 \%$ & $22.7 \%$ & $32.2 \%$ \\
\hline Hampshire $\mathrm{n}=2 \mathrm{I}$ & $47.6 \%$ & $28.6 \%$ & $23.8 \%$ & $0 \%$ \\
\hline Piétrain $n=28$ & $14.3 \%$ & $28.6 \%$ & $21.4 \%$ & $35.7 \%$ \\
\hline Large White $n=16$ & $37.5 \%$ & $12.5 \%$ & $25.0 \%$ & $25.0 \%$ \\
\hline
\end{tabular}

I) RHS of 0 to 2.1 ; ${ }^{2)} \mathrm{RHS}$ of 2.11 to $10.7 ;{ }^{3)} \mathrm{RHS}$ of $10.7 \mathrm{I}$ to $27.5 ;{ }^{4)} \mathrm{RHS}$ of $27.5 \mathrm{I}$ to $\left.95.61 ; 5\right)$ Eleven German Landrace pigs died or were euthanized outside of days 4 and 20 and, therefore, were not included.

Clinical signs were monitored daily and consisted of an assessment of general appearance (posture, behaviour, feed intake, temperature, vomiting) and respiratory tract (breathing noise, dyspnoea, respiratory frequency, coughing, pulsoxymetric oxygen saturation [Pulsoxymeter NPB40, Fa. Nellcor Puritan Benett Inc., Boulder, U.S.A.] and cyanosis); pulsoxymetric oxygen saturation was measured at the lower side of the tail [33]. Parameters with two specifications (vomiting) were scored with 0 or 4 points, parameters with three specifications (dyspnoe) with 0,2 , or 4 points, parameters with four specifications (breathing noise, coughing, feed intake) with $0,1.33,2,67$, or 4 points, and the remaining parameters with five specifications with $0,1,2,3$, or 4 points [31]. The points were added and divided by 11 to result in the daily clinical score resulting in a score of 0 for a healthy animal and a maximum score of 4 for a severely diseased animal; a dead animal was scored with 5 points. The clinical score on day 4 is the sum of the daily clinical score from days 1 to 4 ; the clinical score on day 20 is calculated accordingly [31].

Ultrasonographic and radiographic examinations of the lungs both were performed under anaesthesia with 15 $\mathrm{mg} / \mathrm{kg}$ Ketamine i.m. (Ursotamin ${ }^{\oplus}$, Fa. Serum-Werk-Bernburg AG, Bernburg, Germany) and $2 \mathrm{mg} / \mathrm{kg}$ i.m. Azaperon (Stresnil ${ }^{\circledR}$, Fa. Janssen-Cilag GmbH, Baar, Switzerland). Ultrasonography of the lungs was performed with an 8 $\mathrm{MHz}$ linear scanner (LOGIQ ${ }^{\mathrm{TM}}$ Book XP, Fa. GE Medical Systems, Chalfont St. Giles, Great Britain) in lateral posi- tion. On either side of the chest each intercostal space was scanned in dorso-ventral direction. Right and left lung are each divided into 5 sections, and each section is subdivided into the intercostal spaces [31]. Comet-tail-artefacts, echogenicity, consolidations, and sequesters were analysed with a point range from 0 (physiological findings) to 8 (no unaltered lung tissue seen). The addition of the score points given for the observed alterations resulted in the sonographic score with a score of 200 being lethal [31].

Radiography was carried out in two views (latero-lateral and dorso-ventral; Convix Generator 360, Fa. Picker Int., Munich, Germany, 400 mAs, $110 \mathrm{kV}, 1000 \mathrm{~ms}$ ) using a shutter priority (Precimat, Fa. Picker Int.). In the radiographic score the lung was divided into eight sections. Bronchial, alveolar and interstitial patterns, cardiac and diaphragm silhouette and sequesters were analysed with a point range from 0 to 3 . The addition of the score points given for the observed alterations resulted in the radiographic score with a score of 50 being lethal [31].

\section{Development of a Respiratory Health Score (RHS)}

For quantification of the examination results the Respiratory Health Score (RHS) was developed based on a combination of the clinical, sonographic and radiographic scores. The RHS is a score that indicates the degree of lung alteration in percent of the maximum alteration possible in a live animal. Briefly, individual scores are normalized

Table 3: RHS-based distribution of pigs from different breeding lines into ranking quartiles on on day 20 post infection

\begin{tabular}{|c|c|c|c|c|}
\hline & (st quartilel) & $2^{\text {nd }}$ quartile 2$)$ & $3^{\text {rd }}$ quartile 3 ) & $4^{\text {th }}$ quartile ${ }^{4)}$ \\
\hline German Landrace $\left.^{5}\right) n=18$ & $21.1 \%$ & $10.5 \%$ & $31.6 \%$ & $36.8 \%$ \\
\hline Hampshire $\mathrm{n}=1 \mathrm{I}$ & $45.5 \%$ & $54.5 \%$ & $0 \%$ & $0 \%$ \\
\hline Piétrain $n=16$ & $13.4 \%$ & $26.6 \%$ & $33.4 \%$ & $26.6 \%$ \\
\hline
\end{tabular}

1) RHS of 0.21 to $\left.3.33 ;{ }^{2}\right) \mathrm{RHS}$ of 3.34 to $18.8 ;{ }^{3)} \mathrm{RHS}$ of 18.8 I to 34.91 ; ${ }^{4)} \mathrm{RHS}$ of 34.92 to 99.12 ; 5 ) Eleven German Landrace pigs died or were euthanized outside of days 4 and 20 and, therefore, were not included. 
by division with the score causing death in an animal, added, divided by three and multiplied by 100 in order to get a value in percent (Fig. 1). Therefore, the RHS has a possible range from 0 to $100 \%$.

\section{Statistical analysis}

For statistical analyses of the data SAS ${ }^{\circledast}$ software (SAS Institute Inc., Cary, NC, USA) was used. Correlations of i) LLS and RHS and ii) RHS on days 4 and day 20 post infection were assessed by calculating the Spearman Rank Correlation Coefficient.

\section{Authors' contributions}

DH participated in the design and carried out the clinical studies, performed the statistical analysis, participated in the development of the Respiratory Health Score and drafted the manuscript. IHP participated in the design of the studies and helped to draft the manuscript. KT participated in the clinical studies. TR organized all clinical studies and carried out the aerosol infection. MB developed the Respiratory Health Score. KSM carried out and interpreted the serological testing of all pigs entering the study. GFG conceived of and designed the studies, participated in their coordination and helped to draft the manuscript. KHW participated in the design and the coordination of the studies.

\section{Acknowledgements}

This research was supported by the Development Association for Biotechnology (FBF) and the German Ministry of Education and Research (BMBF) (FUGATO, IRAS FKZ 0313389 A-E).

other IRAS members are: Hannover Medical School, Helmholtz Centre for Infection Research Braunschweig, Max Planck Institute for Molecular Genetics, Otto-von-Guericke University Magdeburg, LIONEX GmbH Braunschweig, RZPD GmbH Berlin, and the contributing scientists (in alphabetical order) Benga L, Blöcker H, Danilowicz E, Drungowski M, Herwig R, Kahlisch D, Leeb T, Martinez R, Naim HY, Pabst R, Probst I, Radelof U, Rothkötter HJ, Singh M, Spallek R, Stanke F, Tümmler B, Valentin-Weigand $\mathrm{P}$, Wagner $\mathrm{F}$.

\section{References}

I. Altrock Av: Occurrence of bacterial agents in lungs of pigs and evaluation of their resistance to antibiotics. Berl Munch Tierarztl Wschr 1998, I I I: 164-172.

2. Ross RF: Mycoplasma disease. In Disease of Swine 7th edition. Edited by: Leman AD, Straw B, Glock R, Mengeling WL, D'Allaire S, Taylor DJ. Ames, lowa State University Press; 1992:552-559.

3. Sebunya TNK, Saunders JR: Haemophilus pleuropneumoniae infection in swine: a review. J Am Vet Med Assoc 1983, 182: |33|-|337.

4. Noyes EP, Feeney D, Pijoan C: Comparison of the effect of pneumonia detected during lifetime with pneumonia detected at slaughter on growth in swine. J Am Vet Med Assoc 1990, 197:1025-1029.

5. Fenwick B, Henry S: Porcine pleuropneumonia. J Am Vet Med Assoc 1994, 204:1334-1340.

6. Higgins R, Lariviere S, Mittal KR, Martineau GP, Rousseau P, Cameron $\mathrm{J}$ : Evaluation of a killed vaccine against porcine pleuropneumonia due to Haemophilus pleuropneumoniae. Can Vet $J$ 1985, 26:86-89.
7. White DG, Zhao S, Simjee S, Wagner DD, McDermott PF: Antimicrobial resistance of foodborne pathogens. Microbes Infect 2002, 4:405-4I2.

8. Borowy N: Ist das Schwein gesund, freut sich der Verbraucher. Leibnitz Nordost 2005, 1:9-10.

9. Van Oirschot JT: Vaccination in food animal populations. Vaccine 1994, | 2:4|5-4|8.

10. Sutherland MA, Rodriguez-Zas SL, Ellis M, Salak-Johnson JL: Breed and age affect baseline immune traits, cortisol and performance in growing pigs. J Anim Sci 2005, 83:2087-2095.

II. Meijerink E, Fries R, Vögeli P, Masabandra J, Wigger G, Stricker C, Neuenschwander S, Bertschinger HU, Stranzinger G: Two alpha $(I, 2)$ fucosyltransferase genes on porcine chromosome $6 \mathrm{qII}$ are closly linked to the blood group inhibitor $\mathrm{S}$ and Escherichia coli FI 8 receptor (ECFI8R) loci. Mamm Genome 1997, 8:736-741.

12. Voegeli P, Meijerink E, Fries R, Neuenschwander S, Vorlander N, Stranzinger G, Bertschinger HU: [A molecular test for the detection of E. coli FI8 receptors: a breakthrough in the struggle against edema disease and post-weaning diarrhea in swine]. Schweiz Arch Tierheilkd 1997, 139(I I):479-484.

13. Reiner G, Melchinger E, Kramarowa M, Pfaff E, Büttner M, Saalmüller $\mathrm{A}$, Geldermann H: Detection of quantitative trait loci for resistance/susceptibility to pseudorabies virus in swine. J Gen Virol 2002, 83:167-172.

14. Reiner G, Willems H, Berge T, Fischer R, Köhler F, Hepp S, Hertrampf B, Kliemt D, Daugschies A, Geldermann H, Mackenstedt U, Zahner $\mathrm{H}$ : Mapping of quantitative trait loci for resistance/susceptibility to Sarcocystis miescheriana in swine. Genomics 2007, 89:638-646.

15. Cole RK: Studies on genetic resistance to Marek's disease. Avian Dis 1968, 1 2:9-28.

16. Stear MJ, Wakelin D: Genetic resitance to parasitic infection. Rev sci tech Off Int Epiz 1998, 17:143-153.

17. Heringstad B, Klemetsdal G, Ruane J: Selection for mastitis resitance in daity cattle: a review with focus on the situation in the Nordic countries. Livestock Prod Sci 2000, 64:95-106.

18. Opriessnig T, Fenaux M, Thomas P, Hoogland MJ, Rothschild MF, Meng XJ, Halbur PG: Evidence of breed-dependend differences in susceptibility to porcine circovirus type-2-associated disease and lesions. Vet Pathol 2006, 43:28I-293.

19. Vincent AL, Thacker BL, Halbur PG, Rothschild MF, Thacker EL: An investigation of susceptibility to porcine reproductive and respiratory syndrome virus between two genetically diverse commercial lines of pigs. J Anim Sci 2006, 84:49-57.

20. Halbur P, Rothschild MF, Thacker B: Differences in susceptibility of Duroc, Hampshire and Meishan pigs to infection with high-virulence strain (VR2385) of porcine reproductive and respiratory syndrome virus (PRRSV). J Anim Breed Genet 1998, II I: $181-189$.

2I. Petry DB, Holl JW, Weber JS, Doster AR, Osorio FA, Johnson RK: Biological response to porcine respiratory and reproductive syndrome virus in pigs of two genetic populations. J Anim Sci 83:| $1494-1502$.

22. Petry DB, Lunney J, Boyd P, Kuhar D, Blankenship E, Johnson RK: Differential immunity in pigs with high and low response to porcine reproductive and respiratory syndrome virus infection. J Anim Sci 2007, 85:2075-2092.

23. Jones JET: The incidence and nature of diseases causing death in pigs aged 2-7 month in a commercial herd. Br Vet J 1968, 1 25:492-505.

24. Straw BE, Neubauer GD, Leman AD: Factors affecting mortality in finishing pigs. J Am Vet Med Assoc 1983, 183:452-455.

25. Lundeheim N: Genetic analysis of respiratory diseases in pigs. Acta Agric Scand 1979, 29(3):209-215.

26. Jorgensen B: Group-level effects of breed and sire on diseases and influence of diseases on performance of pigs in Danish test stations. Prev Vet Med 1992, I4(3-4):28I-292.

27. Baltes N, Topitak W, Gerlach GF, Hennig-Pauka I, Hoffmann-Moujahid M, Ganter M, Rothkotter HJ: Actinobacillus pleuropneumoniae iron transport and urease activity: effects on bacterial virulence and host immune response. Infect Immun 200I, 69:472-478.

28. Baltes N, Hennig-Pauka I, Jacobsen I, Gruber AD, Gerlach GF: Identification of dimethyl sulfoxide reductase in Actinobacillus 
pleuropneumoniae and its role in infection. Infect Immun 2003, 7I:6784-6792

29. Baltes N, Tonpitak W, Hennig-Pauka I, Gruber AD, Gerlach GF: Actinobacillus pleuropneumoniae serotype 7 siderophore receptor FhuA is not required for virulence. FEMS Microbio Lett 2003, 220:4I-48.

30. Jacobsen I, Hennig-Pauka I, Baltes N, Trost M, Gerlach GF: Enzymes involved in anaerobic respiration appaer to play a role in Actinobacillus pleuropneumoniae virulence. Infect Immun 2005 73:226-234

31. Hoeltig D, Hennig-Pauka I, Thies K, Rehm T, Gerlach GF, Waldmann $\mathrm{KH}$ : Comparison of the diagnostic statement of clinical, radiographic and ultrasonographic results after an experimenta infection with Actinobacillus pleuropneumoniae in pigs. Berl Munch Tierarztl Wochenschr 2008, I 2 I (I I// 2):422-43I.

32. Hannan PC, Bhogal BS, Fish JP: Tylosin tartrate and tiamutilin effects on experimental piglet pneumonia induced with pig lung homogenate containing mycoplasmas, bacteria and viruses. Res Vet Sci 1982, 33:76-88.

33. Dudziak D: Klinische Verlaufskontrolle einer oralen Chlortetrazyklinbehandlung bei lungenkranken Schweinen mittels Röntgendiagnostik und Pulsoxymetrie. Dissertation, Tieraerztliche Hochschule Hannover Hannover 1995 [http://elib.tiho-han nover.de/dissertations/95dudziak-d.pdf].

34. Gierke Kv: Klinische Diagnostik von Lungenerkrankungen beim Schwein mit besonderer Berücksichtigung der Röntgenuntersuchung im Vergleich mit pathologisch-anatomischen Befunden. Dissertation, Tieraerztliche Hochschule Hannover 1997 [http://elib.tiho-hannover.de/dissertations/97gierke-von-k.pdf].

35. Heinritzi K, Beisl J: The application of sonography for swine. Dtsch Tierarztl Wschr 1995, 102:4-15.

36. Schulze W, Schröder I, Arbeiter K: The respiratory rate of the pig. Dtsch Tierarztl Wschr 1963, 22:620-624.

37. Farrow CS: Equine thoracic radiology. J Am Vet Med Assoc I98I, 179:61|-615.

38. Farrow CS: Radiography of the equine thorax: anatomy and technic. Vet Radiol 1981, 22:62-68.

39. Klein C: Sonographie der Lunge und Analyse der Atmungsmechanik mittels Impuls-Oszilloresistometrie beim lungengesunden und pneumoniekranken Ferkel und Läuferschwein. In Dissertation Universität Leipzig; 1999.

40. Reef VB, Boy MG, Reid CF, Elser A: Comparison between diagnostic ultrasonography und radiography in evaluation of horses und cattle with thoracic disease: 56 cases (1984 1985). J Am Vet Med Assoc 1991, 198:2112-2117.

41. Reinhold P, Rabeling B, Günther H, Schimmel D: Comparative evaluation of ultrasonography and lung function testing with the clinical signs and pathology of calves inoculated experimentally with Pasteurella multocida. Vet $\operatorname{Rec} 2002$, I 50 : I09-I I 4.

42. Tobin E: Thoracic radiology part I: the respiratory system pleural space and mediastinum. Ir Vet / 2004, 57:598-604.

43. Magnusson U, Bosse J, Mallard BA, Rosendal S, Wilkie BN: Antibody response to Actinobacillus pleuropneumoniae antigens after vaccination of pigs bred for high and low immune response. Vaccine 1997, 15:997-1000.

44. Magnusson U, Wilkie B, Mallard B, Rosendal S, Kennedy B: Mycoplasma hyorhinis infection of pigs bred for high and low immune response. Vet Immun Immunpathol 1998, 1:83-96.

45. Done $\mathrm{SH}$ : Environmental factors affecting the severity of pneumonia in pigs. Vet $\operatorname{Rec} 199 \mid$, | 28:582-586.

46. Waldmann $\mathrm{KH}$ : Housing- and management-specific effects on the health of swine. Dtsch Tierarztl Wschr 2003, I I 0:328-330.

47. Benga L, Hoeltig D, Rehm T, Rothkoetter HJ, Pabst R, Valentin-Weigand $P$ : Expression levels of immune markers in Actinobacillus pleuropneumoniae infected pigs and their relation to breed and clinical symptoms. BMC Vet Res 5:13

48. Leiner G, Franz B, Strutzberg K, Gerald GF: A novel enzymelinked immunosorbent assay using the recombinant Actinobacillus pleuropneumoniae ApxII antigen for diagnosis of pleuropneumonia in pig herds. Clin Diagn Lab Immunol 1999 , 6:630-632

49. Dreyfuß A, Schaller A, Nivollet S, Segers RPAM, Kobisch M, Mieli L, Soerensen V, Hussy D, Miserez R, Zimmermann W, Inderbitzin F, Frey J: Use of recombinant ApxIV in serodiagnosis of Actinobacillus pleuropneumoniae infections, development and prevalidation of the Apx IV Elisa. Vet Microbiol 2004, 99:227-238.
50. Jacobsen MJ, Nielsen JP, Nielsen R: Comparison of virulence of different Actinobacillus pleuropneumoniae serotypes and biotypes using an aerosol infection model. Vet Microbiol 1996, 49:159-168

5I. Maas A, Meens J, Baltes N, Hennig-Pauka I, Gerlach GF: Development of a DIVA subjunit vaccine against Actinobacillus pleuropneumoniae infection. Vaccine 2006, 24:7226-7237.
Publish with Biomed Central and every scientist can read your work free of charge

"BioMed Central will be the most significant development for disseminating the results of biomedical research in our lifetime. "

Sir Paul Nurse, Cancer Research UK

Your research papers will be:

- available free of charge to the entire biomedical community

- peer reviewed and published immediately upon acceptance

- cited in PubMed and archived on PubMed Central

- yours - you keep the copyright 